\title{
Left sinus of Valsalva aneurysm: Rare disease, rarer presentation
}

\author{
Wan Kee Kim, MD, and Joon Bum Kim, MD, PhD
}

\footnotetext{
From the Department of Thoracic and Cardiovascular Surgery, Asan Medical Center, University of Ulsan College of Medicine, Seoul, Korea.

Disclosures: Authors have nothing to disclose with regard to commercial support.

Received for publication Oct 13, 2018; accepted for publication Oct 15, 2018; available ahead of print Nov 22 , 2018.

Address for reprints: Joon Bum Kim, MD, PhD, Department of Thoracic and Cardiovascular Surgery, Asan Medical Center, University of Ulsan College of Medicine 88, Olympic-ro 43-gil, Songpa-gu, Seoul 05505, Republic of Korea (E-mail: jbkim1975@amc.seoul.kr).

J Thorac Cardiovasc Surg 2019;157:e169-70

$0022-5223 / \$ 36.00$

Copyright (c) 2018 by The American Association for Thoracic Surgery

https://doi.org/10.1016/j.jtcvs.2018.10.070
}

Sinus of Valsalva aneurysm (SVA) is rare condition, with a reported prevalence of around $0.09 \%$ of the general population. ${ }^{1}$ A landmark embryologic study revealed the etiology of SVA, demonstrating incomplete fusion between the bulbar septum and truncal ridges. ${ }^{2}$ As a result, the defect in the media of the sinus of Valsalva follows, with resultant aneurysmal change of the aortic wall. Although most SVAs are discovered by a sudden rupture or are detected incidentally during a regular checkup, some subset of patients present with symptoms of left-to-right shunt, aortic valve insufficiency, or mass effects. ${ }^{3}$

The reported origins of SVA have been predominantly the right coronary sinus, followed by noncoronary sinus (around 15\%) and the left coronary sinus $(<5 \%) .{ }^{4}$ In this issue of the Journal, Sarkar and his colleagues ${ }^{5}$ report a rare case of SVA on the left coronary sinus, which caused myocardial ischemia by a stretching of the left main coronary artery. Sarkar and his colleagues ${ }^{5}$ performed bioBentall and coronary arterial bypass grafting procedures. Surgical planning of myocardial revascularization seems reasonable, because the usual coronary button reattachment technique may not properly address the narrow, stretched left main coronary artery. Although previous case reports have shown left SVAs compressing the left main coronary artery, ${ }^{6,7}$ the case of Sarkar and colleagues ${ }^{5}$ may be unique in its characteristics - myocardial ischemia was caused by narrow, stretched distortion by a left SVA. In this particular case, the left SVA of a 64-year-old patient seemed not have ruptured for a long period, despite its extensive size, which may correlate well with other previous cases of huge left SVA found in patients at advanced age ( $>50-60$ years). ${ }^{6-8}$ Interestingly, patients with noncoronary or right SVAs usually present with rupture at the age of 20 to 40 years, according to reported series. ${ }^{3}$ This seemingly significant age difference between left SVA and SVA at other sites needs further investigation regarding modes of disease progression and detection. Some argue that the rupture of left

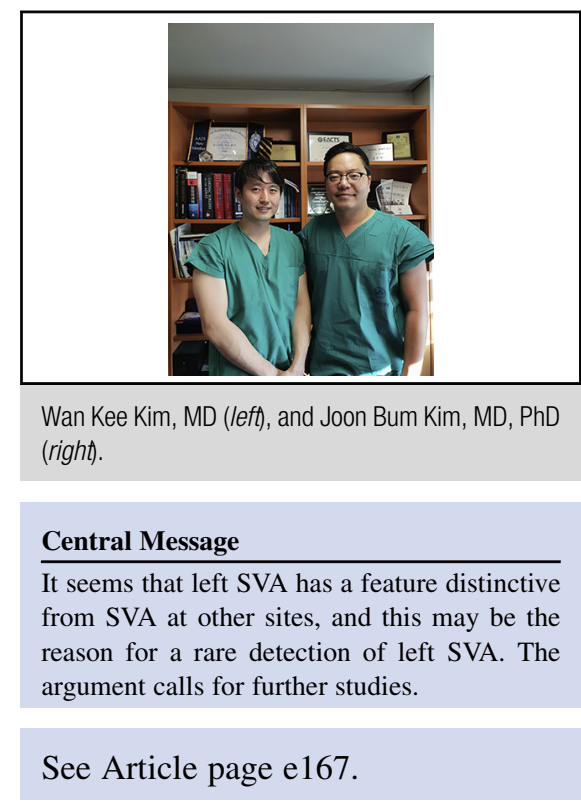

SVA is clinically less malignant, because it tends to make communication to the left atrium and left ventricular outflow tract. ${ }^{9}$ This may be one of the reasons for a delayed detection of the left SVA compared with other types.

In our own review, however, reports on the rupture occurring in the left SVA itself seem extremely rare (only 2 of 8 cases), and the reports seem to be much rarer than its own prevalence. It can also be considered that, unlike right SVA rupture, left SVA rupture into extracardiac space can be highly fatal because of the lack of adjacent rigid structure in the posterior aspect, which may lead to sudden death without a chance for diagnosis. On the basis of previous series, it seems clear that mass effects (mainly coronary compression) are the predominant drivers for the left SVA to be diagnosed. This is a distinctive feature from SVA at other sites, and it may be the reason why left SVAs are detected rarely or are found at advanced ages. These arguments call for further studies to understand better the differential pathophysiology of SVA occurring in the left coronary sinus.

\section{References}

1. Hope J, ed. A Treatise on the Disease of the Heart and Great Vessels. 3rd ed. Philadelphia PA: Lea and Blanchard; 1839:466-71.

2. Edwards JE, Burchell HB. The pathological anatomy of deficiencies between the aortic root and the heart, including aortic sinus aneurysms. Thorax. 1957;12: 125-39.

3. Weinreich M, Yu PJ, Trost B. Sinus of Valsalva aneurysms: review of the literature and an update on management. Clin Cardiol. 2015;38:185-9. 
4. Ring WS. Congenital heart Surgery nomenclature and database project: aortic aneurysm, sinus of Valsalva aneurysm, and aortic dissection. Ann Thorac Surg. 2000;69(4 Suppl):S147-63.

5. Sarkar M, Wehman B, Mukherjee R, Taylor BS. Left sinus of Valsalva aneurysm presenting as myocardial ischemia. J Thorac Cardiovasc Surg. 2019;157:e167-8.

6. Pedroza AJ, Brewer ZE, Lee AM. Emergency valve-sparing aortic root replacement and coronary artery bypass grafting for giant left sinus of Valsalva aneurysm presenting as acute coronary syndrome. J Thorac Cardiovasc Surg. 2018;156:e81-4.
7. Martínez-Comendador J, Gualis J, Martín CE, Santamaria A. Left main coronary artery compression by a left sinus of Valsalva aneurysm. Interact Cardiovasc Thorac Surg. 2013;16:713-4.

8. Ponti A, Quanadli SD, Kirsch M, Tapponnier M. Left sinus of Valsalva aneurysm as a cause of chronic stable angina. Interact Cardiovasc Thorac Surg. 2017;24:967-8.

9. DeMaria AN, Blanchard DG. Echocardiography. In: Fuster V, Walsh RA, Harrington RA, eds. Hurst's the Heart. 13th ed. New York: McGraw-Hill; 2011 